Article

\title{
Fruit Morphology, Citrulline, and Arginine Levels in Diverse Watermelon (Citrullus lanatus) Germplasm Collections
}

\author{
Awraris Derbie Assefa ${ }^{1}{ }^{1}$, On-Sook Hur ${ }^{1}$, Na-Young Ro ${ }^{1}$, Jae-Eun Lee ${ }^{1}$, Ae-Jin Hwang ${ }^{1}$, \\ Bich-Saem Kim ${ }^{1}$, Ju-Hee Rhee ${ }^{1}$, Jung-Yoon $\mathrm{Yi}^{1}{ }^{1}$, Ji-Hyun Kim ${ }^{1}$, Ho-Sun Lee ${ }^{2}$, Jung-Sook Sung ${ }^{3}$, \\ Myung-Kon Kim ${ }^{4}$ (D) and Jae-Jong Noh ${ }^{5, *(D)}$ \\ 1 National Agrobiodiversity Center, National Institute of Agricultural Sciences, RDA, Jeonju 54874, Korea; \\ awrarisderbie@gmail.com (A.D.A.); oshur09@korea.kr (O.-S.H.); nonanona@korea.kr (N.-Y.R.); \\ jnlee88@korea.kr (J.-E.L.); hyj6138@korea.kr (A.-J.H.); bsam92@korea.kr (B.-S.K.); rheehk@korea.kr (J.-H.R.); \\ naaeskr@korea.kr (J.-Y.Y.); wlsghfla5158@naver.com (J.-H.K.) \\ 2 International Technology Cooperation Center, RDA, Jeonju 54875, Korea; hosun83@korea.kr \\ 3 Upland Crop Breeding Division, Department of Southern Area Crop Science, National Institute of Crop \\ Science, RDA, Miryang 50424, Korea; sjs31@korea.kr \\ 4 Department of Food Science and Technology, Jeonbuk National University, Jeonju 54896, Korea; \\ kmyuko@jbnu.ac.kr \\ 5 Jeonbuk Agricultural Research and Extension Services, Iksan 54591, Korea \\ * Correspondence: nohjj@korea.kr; Tel.: +82-63-290-6121
}

Received: 10 July 2020; Accepted: 16 August 2020; Published: 19 August 2020

\begin{abstract}
Watermelon (Citrullus lanatus) is a non-seasonal, economically important, cucurbit cultivated throughout the world, with Asia as a continent contributing the most. As part of the effort to diversify watermelon genetic resources in the already cultivated group, this study was devoted to providing baseline data on morphological quality traits and health-beneficial phytonutrients of watermelon germplasm collections, thereby promoting watermelon research and cultivation programs. To this end, we reported morphological traits, citrulline, and arginine levels of watermelon genetic resources obtained from the gene bank of Agrobiodiversity Center, Republic of Korea, and discussed the relationships between each. Diverse characteristics were observed among many of the traits, but most of the genetic resources $(>90 \%)$ were either red or pink-fleshed. Korean originated fruits contained intermediate levels of soluble solid content (SSC) while the USA, Russian, Tajikistan, Turkmenistan, Taiwan, and Uruguay originated fruits had generally the highest levels of soluble solids. The citrulline and arginine contents determined using the High Performance Liquid Chromatography (HPLC) method ranged from 6.9 to $52.1 \mathrm{mg} / \mathrm{g}$ (average, $27.3 \mathrm{mg} / \mathrm{g}$ ) and 1.8 to $21.3 \mathrm{mg} / \mathrm{g}$ (average, $9.8 \mathrm{mg} / \mathrm{g}$ ), respectively. The citrulline content determined using the Citrulline Assay Kit ranged from 6.5 to $42.8 \mathrm{mg} / \mathrm{g}$ (average, $27.0 \mathrm{mg} / \mathrm{g}$ ). Resources with high citrulline and arginine levels contained low SSC, whereas red- and pink-colored flesh samples had less citrulline compared to yellow and orange.
\end{abstract}

Keywords: genetic resources; fruit morphological characterization; flesh color; principal component analysis; Citrulline Assay Kit; HPLC

\section{Introduction}

Watermelon (Citrullus lanatus) is a cucurbit crop cultivated all over the world. In the year 2018 alone, a production area of 3.2 million ha was utilized, and 103 million tons of watermelons were produced throughout the world. Asia, as a continent, contributed to $81 \%$ of the total production, where Korea produced 534,401 tons (0.5\%) in the same year (Food and Agricultural Organization of 
the United Nations (FAO). Watermelon is regarded to be among the top important horticultural crops in South Korea [1]. It is a non-seasonal fruit grown in areas with long frost-free warm periods [2]. Watermelon fruits are produced in different sizes, shapes, rind patterns, flesh colors, and types based on the cultivar. Watermelon fruit is $93 \%$ water with small amounts of protein, fat, minerals, and vitamins, and with main nutritional components including, carbohydrates, vitamin A, lycopene, and $\beta$-carotene $[2,3]$. The contents of the metabolites in watermelon fruit varies with cultivar, ploidy, genotype, flesh color, and fruit anatomy [4-9]. The flesh of watermelon fruits is consumed in many parts of the world and is proven to be beneficial for disease prevention partly due to the presence of vitamins, lycopene, and amino acids such as citrulline and arginine.

Citrulline and arginine are naturally occurring amino acids in watermelon. Several reports indicate that both exhibit beneficial effects on plant metabolism and human health $[3,10]$. Citrulline is unusually abundant in watermelon, more than any other plant taxon recorded to date $[5,8]$. It is also available in most cucurbits, including bitter melon, cucumber, muskmelon, pumpkin, bottle gourd, dishrag gourd, and wax gourd [8,11]. Drought-tolerant watermelon accumulates high levels of citrulline in response to oxidative stress caused by drought conditions [10]. Citrulline is implied to have an important role in nitrogen translocation during germination [12]. Citrulline is used to regenerate arginine - an aminoacid that displays remarkable metabolic regulatory functions $[13,14]$. Arginine reverses endothelial dysfunction, enhances wound healing, prevents the early stages of tumorigenesis, and improves cardiovascular, reproductive, pulmonary, renal, digestive, and immune functions [15]. In rats, watermelon extract and arginine were shown to improve cardiovascular disease risk factors [16]. Since oral administration of free arginine could result in side effects such as nausea, gastrointestinal discomfort, and diarrhea in humans $[17,18]$, citrulline can be more efficient in diseases related to arginine deficiencies due to its increased bioavailability, better absorption into the bloodstream, and reduced side-effects [8]. Citrulline efficiently scavenges the hydroxyl radical and effectively protects DNA and an enzyme from oxidative injuries [10], and can also exert a positive effect on vasodilation [5]. In vivo studies have indicated that watermelon juice containing citrulline reduced muscle soreness and improved athlete performance [19].

Due to a constant increase in the human population, the demand for high yielding, disease-resistant, and high-nutritive food crops, including watermelon, is intensified. To meet this demand, numerous research and cultivation programs are undergoing research on the conservation and collection of genetically diverse watermelon germplasm, the characterization of quality traits and metabolites, and breeding programs. To diversify the narrow genetic base in terms of important quality traits, morphological characters, and health beneficial phytonutrients, identifying and incorporating new genetic resources available within the watermelon germplasm collections in gene banks into the cultivated crop is crucial. Several reports on the diversity of watermelon genetic resources with regard to their morpholgical traits are available in the literature [20-22]. Studies related to biochemical traitsm such as citrulline on germplasm collections, are elusive and and are mostly limited to cultivars $[6,8,23]$. This study could be of paramount importance to plan future germplasm related studies including trait profiling \& characterization and breeding programs, which in turn improve the current level of production, marketability, and nutraceutical effect of watermelon fruits. The main objectives of our study are (a) to characterize 100 watermelon accessions and seven commercial varieties for their fruit morphological characteristics and determine the contents of two important phytonutrients, citrulline (2-amino-5-(carbamoylamino)pentanoic acid) and arginine (2-amino-5-guanidinopentanoic acid); (b) to evaluate the relationship between these metabolites with some selected fruit morphological characters.

\section{Materials and Methods}

\subsection{Reagents and Chemicals}

A Citrulline Assay Kit containing citrulline standard (240 mM), SDS solution, Proteinase K solution, Assay reagent A, and Assay Reagent B was purchased from Cell Biolabs, Inc. (San Diego, 
CA, USA). Citrulline and arginine standards for High Performance Liquid Chromatography (HPLC) analysis were purchased from Sigma-Aldrich (St. Louis, MO, USA). All solvents and reagents used in extraction and analysis were HPLC grade.

\subsection{Plant Material}

\subsubsection{Cultivation}

Seeds of seven commercial cultivars and 100 watermelon germplasm collections, originating from 22+ countries (AZE, BRA, CHN, IND, IRQ, ITA, JPN, KAZ, KGZ, KOR, MNG, NPL, PHL, RUS, TJK, TKM, TUR, TWN, UKR, URY, USA, UZB, and unknown origin) were obtained from the gene bank of the National Agrobiodiversity Center (NAC), Rural Development Administration (RDA), Jeonju, South Korea. Accession numbers, origin, some selected morphological characters, and photos of the genetic resources investigated in this study are presented as Supplementary Material 1 (Table S1) and 2 (Figure S1). Seeds were sown at a research farm of the NAC in Gochang, Republic of Korea. RDA's recommended cultural management practices for watermelon were followed in the experimental field. Fertilizers were applied $\left(\mathrm{N}-\mathrm{P}_{2} \mathrm{O}_{5}-\mathrm{K}_{2} \mathrm{O}=13.8-4.9-8.7 \mathrm{~kg} / 10 \mathrm{a}\right)$ followed by RDA's standard and drip irrigation tape, which was used for watering. Seeds were sown on 9 April 2019, and were grown in a nursery bed for 37 days. Seedlings (twelve plants from each accession) were transplanted at an area of $35 \mathrm{~cm} \times 300 \mathrm{~cm}$ in a polyethylene film house equipped with an insect net to prevent insect pollination. Plants of the same accession were grown in a single plot (plot area $12.6 \mathrm{~m}^{2}$ ). They were pollinated by hand and harvested after 45 days (on average) of pollination.

\subsubsection{Sampling}

Fruits of the watermelon were harvested at a fully mature stage when the commercial varieties are ready to eat after 45 days of pollination (accumulated temperature of $1000^{\circ} \mathrm{C}$ ), collected, stored in polyethylene bags, and immediately transferred to a $-18^{\circ} \mathrm{C}$ walk-in freezer until further processing. Flesh (mesocarp) of the watermelon fruit was carefully separated from the seeds and rind manually, and the edible part was juiced, frozen at $-80{ }^{\circ} \mathrm{C}$, and lyophilized using a vacuum freeze drier (Ilishibiobase, Rijssen, The Netherlands). Lyophilized powdered samples were sealed to prevent moisture absorption and stored at $-20^{\circ} \mathrm{C}$ until analysis.

\subsubsection{Analysis of Morphological Properties}

The morphological characters were evaluated at commercial maturity stage at the field and in the laboratory. Watermelon fruit samples were evaluated for 14 morphological characters based on modified descriptors of The International Union for the Protection of New Varieties of Plants (UPOV) for watermelon fruits [24]. Six quantitative characters (size of pistil scar (SPS), the width of stripes (WS), weight of fruit (WF), length of fruit (LF), width of fruit (WIF), the thickness of outer layer of the pericarp (TP) (measured at the equatorial cross-section), and soluble solids content (SSC)) were evaluated with the help of a meter, digital caliper, digital balance, and a handheld electronic refractometer, as required. Ten to 12 fruit samples were used to measure the quantitative morphological characters.

\subsection{Extraction and Analysis of Citrulline and Arginine}

Extracts were prepared by dissolving $0.05 \mathrm{~g}$ of the freeze-dried powdered samples of watermelon using $10 \mathrm{~mL}$ HPLC grade water in a $15 \mathrm{~mL}$ conical plastic tube. The solution was kept in an automatic shaker for $30 \mathrm{~min}$, centrifuged, and then the supernatant was filtered using a $0.45 \mu \mathrm{m}$ microsyringe filter. Extract solutions were stored at $-20^{\circ} \mathrm{C}$ for subsequent analysis.

The analysis of the citrulline and arginine was conducted using a Waters HPLC system equipped with a 2690 separation module and waters 996 diode array detector (Milford, MA, USA). UV-Vis detection was set at $200 \mathrm{~nm}$, and the column temperature was held at room temperature. Separation of the compounds was done using a Gemini $\mathrm{C}_{18}(3 \mu \mathrm{m}$ partial size, $250 \times 4.6 \mathrm{~mm}$, Phenomenex, Torrance, 
CA, USA) column. The mobile phase was $0.1 \%$ phosphoric acid in an aqueous solution, and the elution mode was isocratic. Flow rate and total run time were set at $0.3 \mathrm{~mL} / \mathrm{min}$ and $15 \mathrm{~min}$, respectively. Extraction and analysis of all the samples were carried out in triplicates. The citrulline and arginine concentrations were calculated using linear calibration functions prepared using the serial dilutions $(0.1,1,10,25,50,100,250,500$, and $1000 \mu \mathrm{g} / \mathrm{mL})$ of commercial standards, and the final results were expressed as milligram per gram $(\mathrm{mg} / \mathrm{g})$ of freeze-dried watermelon sample.

\subsection{Analysis of Citrulline Using Citrulline Assay Kit}

Citrulline was also estimated by using the Citrulline Assay Kit (CAK), a colorimetric assay that measures the amount of citrulline present in biological samples in a 96-well microliter plate format. Briefly, $50 \mu \mathrm{L}$ of the watermelon sample extract (see extraction procedure in Section 2.3) or citrulline standard are treated with sodium dodecyl sulfate (SDS) $(5 \mu \mathrm{L})$ and proteinase $\mathrm{K}(5 \mu \mathrm{L})$ in $2 \mathrm{~mL}$ screwcap tubes. The mixture was mixed thoroughly by pipetting up and down, and was incubated for $2 \mathrm{~h}$ at $37^{\circ} \mathrm{C}$. Assay reagents ( $250 \mu \mathrm{L}$ Assay Reagent A, $50 \mu \mathrm{L}$ Assay Reagent B) were added to each tube, and then the tubes were closed tightly, mixed well, and incubated for $30 \mathrm{~min}$ at $95{ }^{\circ} \mathrm{C}$. The tubes were transferred to $4{ }^{\circ} \mathrm{C}$ and held for five minutes, followed by centrifugation at $18,000 \times g$ for 10 min at room temperature. A measure of $200 \mu \mathrm{L}$ of the supernatant was pipetted to a 96-well plate, and absorbance was read at $550 \mathrm{~nm}$ using a microplate reader spectrophotometer (Molecular Devices, VERSAmax tunable, San Jose, CA, USA). Citrulline concentration in unknown samples was determined by comparison with a predetermined standard curve obtained from the absorbance of serial dilutions $(0,37.5,75,150,300,600,1200,2400 \mu \mathrm{M})$ of the citrulline standard prepared using $0.1 \mathrm{M}$ sodium phosphate buffer (PBS) (pH 7.5).

\subsection{Statistical Analysis}

All experiments were conducted in triplicates. Results were reported as mean \pm standard deviation and expressed in $\mathrm{mg} / \mathrm{g}$ of flesh dry weight (DW). Analysis of variance (ANOVA), followed by the Duncan multiple range tests $(p<0.05)$, conducted using SPSS V 25 statistical program (SPSS Inc., Chicago, IL, USA), was employed to determine the significance of the variation between the mean concentration of each compound between the samples. Correlation analysis was also done using SPSS V 25 statistical program. Principal Component Analysis (PCA) was conducted using R-program (Version 3.6.1, RStudio, Inc., Boston, MA, USA).

\section{Results and Discussion}

\subsection{Fruit Morphological Characteristics}

The variation in qualitative and quantitative morphological characters in 105 watermelon fruit samples is summarized in Table 1. Watermelon fruit samples have portrayed quite a wide range of diversity of fruit size, shape, skin color, flesh color, outer skin patterns, weight, and SSC. Most samples $(94.3 \%)$ had a green ground skin color, and the remaining exhibited white skin. The intensity of the green color of the skin showed quite a range of diversity, which was described in nine levels from very light to very dark. Most of the resources were circular (60.6\%) and broad elliptic (28.8\%) in the longitudinal section. Fruits shapes that were truncated and moderately rounded at the apical part dominated the entire resources studied, comprising $90.5 \%$. Grooving is absent in $85 \%$ of the accessions, and if present, it was mostly on the whole fruit. Only a single material (S/No 41, IT 203049) showed grooving at the basal half. Stripes were conspicuous in $66.7 \%$ of the resources. Considerable variation was observed in the main color of the flesh, where most resources exhibted pink, red, or a mixture of both. Yellow flesh color was observed in five resources, while white-colored flesh watermelon fruits were not observed. In concordance with this study, yellow and white flesh color were quite scarce in previous reports $[20,21,25]$. 
Table 1. Modified International Union for the Protection of New Varieties of Plants (UPOV) descriptors used for morphological characterization of watermelon fruits.

\begin{tabular}{|c|c|c|c|c|c|c|}
\hline No & Trait & Description & Class & $n$ & $\%$ & Min/Max/Ave * \\
\hline \multirow{4}{*}{1} & \multirow{4}{*}{$\begin{array}{l}\text { Fruit shape in } \\
\text { longitudinal section }\end{array}$} & Circular & 1 & 63 & 60.6 & - \\
\hline & & Broad elliptic & 2 & 30 & 28.8 & - \\
\hline & & Medium elliptic & 3 & 9 & 8.7 & - \\
\hline & & Narrow elliptic & 4 & 2 & 1.9 & - \\
\hline \multirow{3}{*}{2} & \multirow{3}{*}{ Ground color of skin } & White & 1 & 6 & 5.7 & - \\
\hline & & Yellow & 2 & 0 & 0.0 & - \\
\hline & & Green & 3 & 99 & 94.3 & - \\
\hline \multirow{9}{*}{3} & \multirow{9}{*}{$\begin{array}{l}\text { Intensity of green } \\
\text { color of skin }\end{array}$} & Very light & 1 & 2 & 1.9 & - \\
\hline & & Very light to light & 2 & 5 & 4.8 & - \\
\hline & & Light & 3 & 3 & 2.9 & - \\
\hline & & Light to medium & 4 & 6 & 5.7 & - \\
\hline & & Medium & 5 & 18 & 17.1 & - \\
\hline & & Medium to dark & 6 & 21 & 20.0 & - \\
\hline & & Dark & 7 & 27 & 25.7 & - \\
\hline & & Dark to very dark & 8 & 13 & 12.4 & - \\
\hline & & Very dark & 9 & 10 & 9.5 & - \\
\hline \multirow{6}{*}{4} & \multirow{5}{*}{$\begin{array}{c}\text { Fruit shape of apical } \\
\text { part }\end{array}$} & Truncate & 1 & 52 & 49.5 & - \\
\hline & & Little rounded & 2 & 43 & 41.0 & - \\
\hline & & Rounded & 3 & 9 & 8.6 & - \\
\hline & & Little acute & 4 & 1 & 1.0 & - \\
\hline & & Acute & 5 & 0 & 0.0 & - \\
\hline & \multirow{4}{*}{$\begin{array}{l}\text { Grooving } \\
\text { distribution of fruit }\end{array}$} & Absent & 1 & 85 & 81.0 & - \\
\hline \multirow{3}{*}{5} & & At basal half & 2 & 1 & 1.0 & - \\
\hline & & At apical half & 3 & 0 & 0.0 & - \\
\hline & & On whole fruit & 4 & 19 & 18.1 & - \\
\hline \multirow{2}{*}{6} & \multirow{2}{*}{$\begin{array}{c}\text { Conspicuousness of } \\
\text { stripes }\end{array}$} & Inconspicuous & 0 & 35 & 33.3 & - \\
\hline & & Conspicuous & 1 & 70 & 66.7 & - \\
\hline \multirow{6}{*}{7} & \multirow{6}{*}{ Main color of flesh } & White & 1 & 0 & 0.0 & - \\
\hline & & Yellow & 2 & 5 & 4.8 & - \\
\hline & & Orange & 3 & 4 & 3.8 & - \\
\hline & & Pink & 4 & 30 & 28.6 & - \\
\hline & & Pink/red & 5 & 37 & 35.2 & - \\
\hline & & Red & 6 & 29 & 27.6 & - \\
\hline 8 & \multicolumn{5}{|c|}{ Size of pistil scar (mm) } & 2.0/32.6/14.1 \\
\hline 9 & \multicolumn{5}{|c|}{ Width of stripes (mm) } & $0.0 / 29.8 / 8.4$ \\
\hline 10 & \multicolumn{5}{|c|}{ Weight of fruit $(\mathrm{kg})$} & $3.2 / 10.4 / 5.2$ \\
\hline 11 & \multicolumn{5}{|c|}{ Length of fruit $(\mathrm{cm})$} & $17.0 / 48.4 / 23.3$ \\
\hline 12 & \multicolumn{5}{|c|}{ Width of fruit(cm) } & $17.3 / 23.2 / 20.7$ \\
\hline 13 & \multicolumn{5}{|c|}{ Thickness of outer layer of the pericarp (mm) } & $4.6 / 22.6 / 10.6$ \\
\hline 14 & \multicolumn{5}{|c|}{ Soluble solids content (Brix) } & $5.1 / 12.3 / 8.5$ \\
\hline
\end{tabular}

Other morphological characters evaluated quantitatively had also shown a wide range of variation. The average, maximum, and minimum values of seven quantitative measurements of watermelon fruit samples are presented in Table 1 . The highest diversity was observed on the width of the stripes (0.0 to $29.8 \mathrm{~mm}$ ), size of the pistil scar (2.0 to $32.6 \mathrm{~mm}$ ), and thickness of the outer layer of pericarp (4.6 to $22.6 \mathrm{~mm}$ ). The WF, SSC, length, and width of the fruit had also shown quite a wide diversity, but the medium character was common in most of the accessions. The average values of SSC, thickness of the outer layer of the pericarp, and length and width of fruits are comparable with previous reports; however, the fruit weight and size of the pistil scar were higher in the resources investigated in our study $[8,20-22,26]$. 
Some morphological characters showed diversity based on the resources country of origin. Analysis of the average quantitative morphological characters showed that Korean origin watermelon fruits were characterized by a smaller size of the pistil scar, conspicuous longer width of stripes, intermediate SSC, red/pink colored flesh, absence of grooves, smaller rounded shape at the apical, and a varied shape at the longitudinal section. On the other hand, stripes are absent in watermelon fruits originating from Iraq, Kyrgyzstan, Mongolia, and Uruguay, while fruits from Italy and Brazil exhibited a longer width of stripes. The USA, Russian, Tajikistan, Turkmenistan, Taiwan, and Uruguay originated fruits had generally higher SSC compared to other origins. Indian, Brazilian, USA, and Chinese originated fruits were larger in weight and length (Supplementary Material Table S1).

Principal Component Analysis (PCA) for the seven quantitative morphological traits was conducted (Figure 1). Results of the Principal Component Analyses (for the first three PC's) of the seven quantitative morphological traits are presented in the Supplementary Material 1 (See Table S2). The first three principal components, with eigenvalues greater than 1, explained 32.0, 23.3, and 19.2\% of the variations, respectively, making a total of $74.5 \%$. Weight and length of fruit and size of the pistil scar were important variables composing PC1, while PC2 was mostly constructed from the width of the fruit, the thickness of the outer layer of the pericarp, size of the pistil scar, and the width of the stripes. The SSC was highly correlated with PC3. Some of the characters showed a significant correlation to each other; for example, the weight of the fruit was highly correlated with the length and width of fruit. Other important significant correlations $(p<0.01)$ worth noting are the size of pistil scar vs. the weight, length, and width of fruit. The size of the pistil scar was negatively correlated with the former two characters, whereas it showed a strong positive correlation with the latter. Thicker pericarp watermelon fruits were also found to possess less SSC, as observed from the PCA and Pearson correlation data (Table 2, Figure 1; Supplementary Material 1, Table S2).

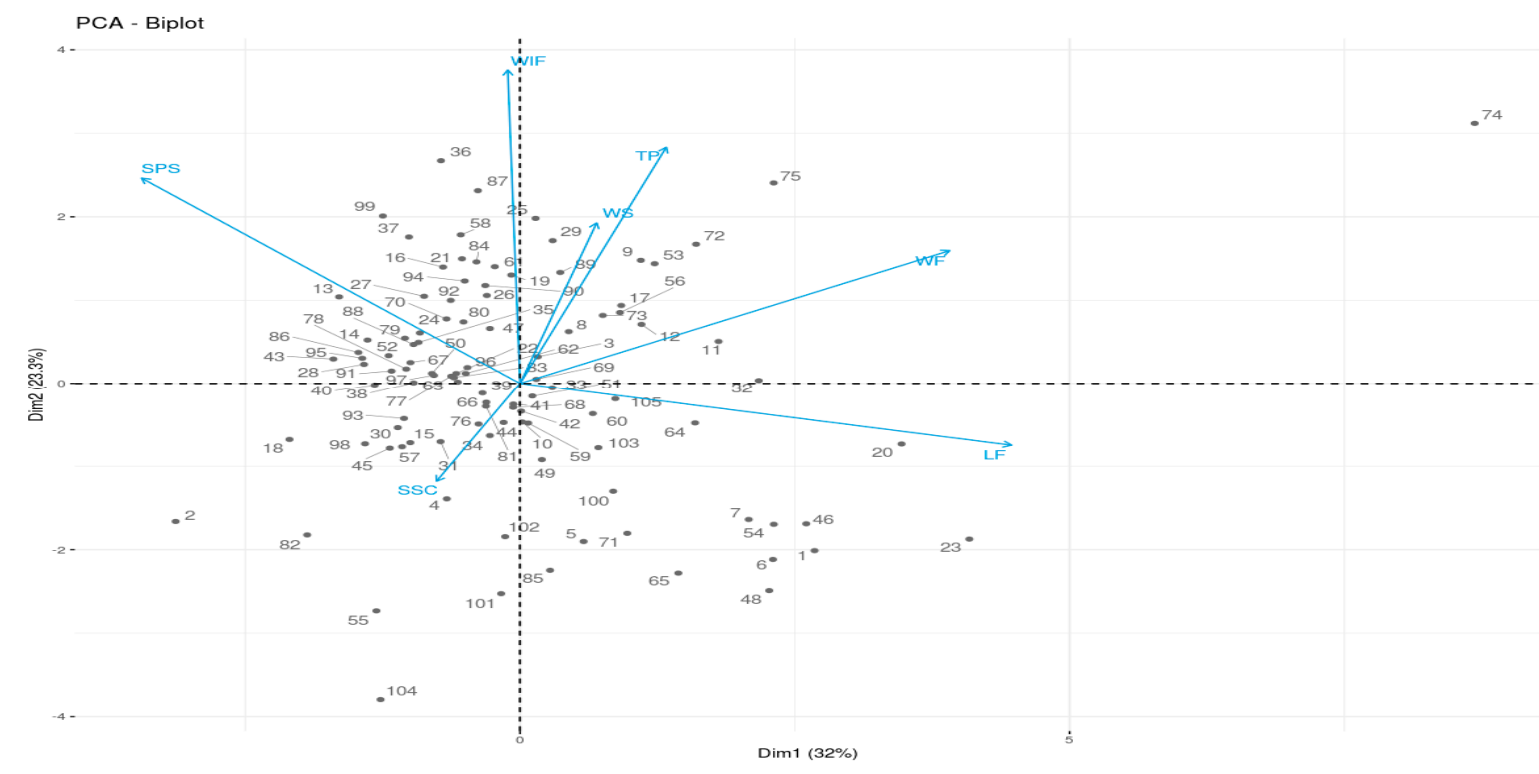

Figure 1. Principal Component Analysis (PCA)-Biplot of watermelon fruit samples with morphological characters measured quantitatively. SPS = Size of pistil scar $(\mathrm{mm}) ; \mathrm{WS}=$ Width of stripes $(\mathrm{mm})$; $\mathrm{WF}=$ Weight of fruit $(\mathrm{kg}) ; \mathrm{LF}=$ Length of fruit $(\mathrm{cm}) ; \mathrm{WIF}=$ Width of fruit $(\mathrm{cm}) ; \mathrm{TP}=$ Thickness of outer layer of pericarp $(\mathrm{mm}) ; \mathrm{SSC}=$ Soluble solids content $($ Brix $)$. 
Table 2. Pearson's correlation coefficient of traits for watermelon genetic resources.

\begin{tabular}{|c|c|c|c|c|c|c|c|c|c|c|}
\hline Trait & SPS & WS & WF & LF & WIF & TP & SSC & Citrulline & Arginine & Citrulline \# \\
\hline WS & 0.020 & - & & & & & & & & \\
\hline WF & $-0.362 * *$ & 0.144 & - & & & & & & & \\
\hline LF & $-0.662 * *$ & 0.052 & $0.737^{* *}$ & - & & & & & & \\
\hline $\mathrm{TP}$ & 0.094 & 0.197 * & 0.174 & 0.191 & 0.146 & - & & & & \\
\hline SSC & -0.013 & 0.142 & -0.026 & -0.094 & 0.046 & $-0.419^{* *}$ & - & & & \\
\hline Citrulline & 0.191 & 0.014 & $-0.235^{*}$ & $-0.203^{*}$ & -0.161 & -0.083 & $-0.375^{* *}$ & - & & \\
\hline $\begin{array}{c}\text { Citrulline + } \\
\text { Arginine }\end{array}$ & 0.172 & -0.103 & -0.166 & -0.133 & -0.152 & -0.021 & -0.452 & 0.926 & 0.624 & 0.874 \\
\hline
\end{tabular}

${ }^{* *}$ Correlation is significant at the 0.01 level (2-tailed); ${ }^{*}$ Correlation is significant at the 0.05 level (2-tailed); SPS $=$ Size of pistil scar $(\mathrm{mm})$; WS = Width of stripes $(\mathrm{mm}) ; \mathrm{WF}=$ Weight of fruit $(\mathrm{kg}) ; \mathrm{LF}=$ Length of fruit $(\mathrm{cm}) ; \mathrm{WIF}=$ Width of fruit $(\mathrm{cm})$; TP = Thickness of outer layer of pericarp $(\mathrm{mm}) ; \mathrm{SSC}=$ Soluble solids content (Brix); ${ }^{\text {* Citrulline content }}$ are determined using Citrulline Assay Kit (CAK).

\subsection{Analysis of Citrulline and Arginine Using HPLC and}

\subsubsection{Method Development and Validation}

The separation and analysis of citrulline and arginine in mixed standard and watermelon extracts were performed using selected mobile phases and a chromatographic column according to earlier reports, but with slight modifications $[8,27,28]$. Citrulline and arginine in watermelon flesh samples were efficiently separated in the Gemini $\mathrm{C}_{18}$ column using $0.1 \%$ phosphoric acid in an aqueous solution as a mobile phase and isocratic elution mode. The Gemini column, a first-generation stationary phase obtained from Phenomenex, is end-capped with porous silica used as a base core, and a layer of embedded silica is coated on the top of the silica core $[28,29]$. In this column and the specified mobile phase condition, arginine and citrulline were eluted at 7.5 and $9.3 \mathrm{~min}$, respectively (Figure 2).

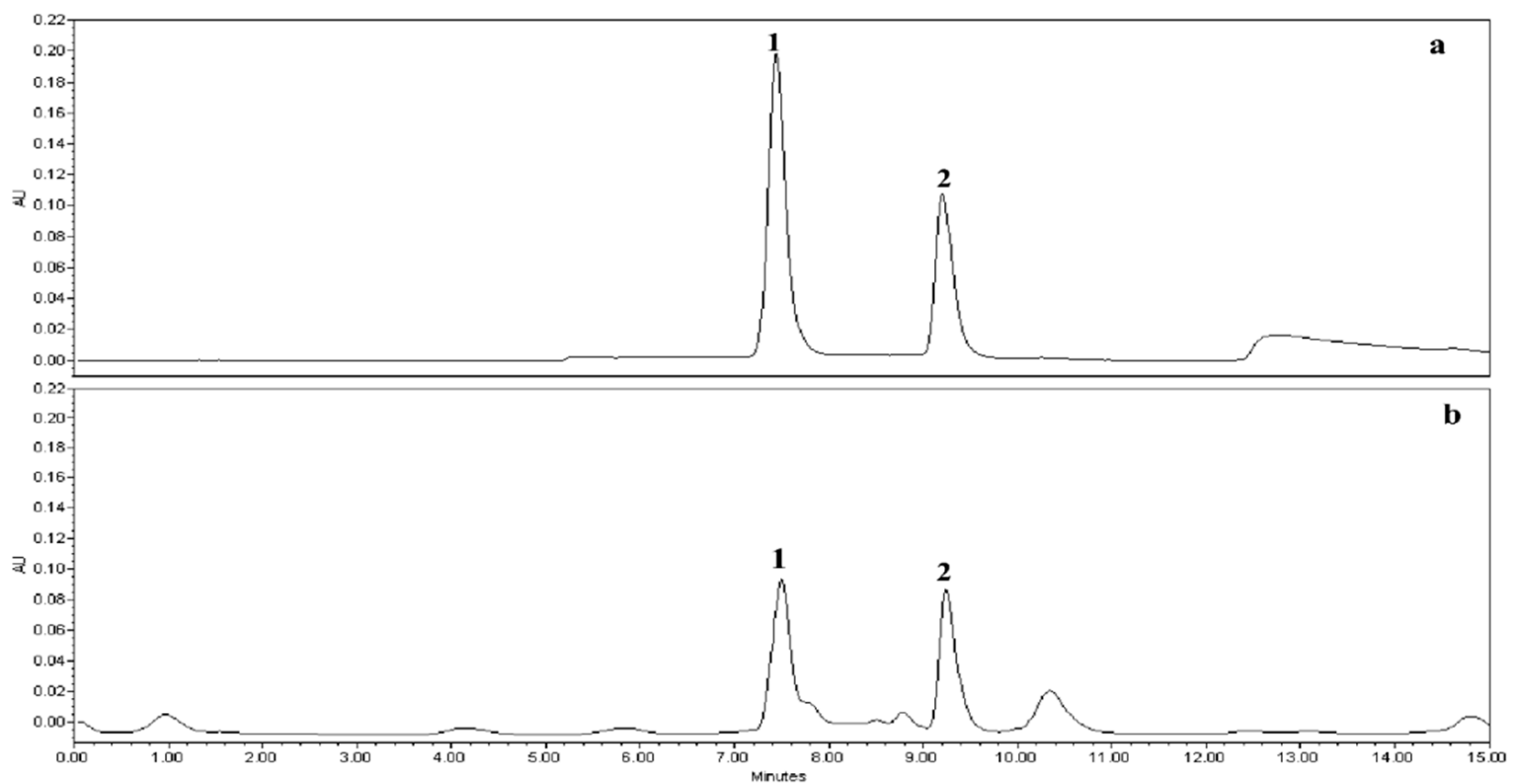

Figure 2. A representative HPLC chromatogram showing the isocratic RP-HPLC separation of arginine (peak 1) and citrulline (peak 2): Mixed standard (a); watermelon fruit sample (b).

Calibration curves were prepared from an average of three independent standard solutions of serial dilutions in a concentration range of $5-500 \mu \mathrm{g} / \mathrm{mL}$ for citrulline and $0.1-1000 \mu \mathrm{g} / \mathrm{mL}$ for arginine versus the peak areas in the HPLC analysis. The linearity of the method for the quantification of citrulline using a Citrulline Assay Kit (CAK) was constructed in the concentration range of 0.3285 to $10.512 \mu \mathrm{g} / \mathrm{mL}$. Regression analysis of the standard experimental data points in the HPLC method 
demonstrated a linear relationship with correlation coefficients $\left(R^{2}\right)$ of 0.999 and 0.997 , and the regression equations of $Y=15716 X-11226$ and $Y=36706 X+383305$ ( $X$ stands for the concentration and $Y$ for peak area), for citrulline and arginine, respectively. The regression equation and correlation coefficients $\left(R^{2}\right)$ for citrulline analysis using CAK were $Y=0.0414 X+0.0785$ (X stands for concentration and $Y$ stands for absorbance) and 0.994 , respectively.

Recovery test, inter- and intra-day precision, and the effect of the sample size were performed using two watermelon fruit samples. The recovery test verified the efficiency of the method for the extraction and analysis of citrulline and arginine. The data obtained by spiking 2 to $10 \mathrm{mg}$ standards showed a mean recovery of 100.70 to $107.71 \%$ for citrulline, 96.47 to $102.28 \%$ for arginine, and 95.68 to $101.75 \%$ for citrulline using CAK, suggesting the reliability and accuracy of the method. Recovery test results are tabulated in Supplementary Material 1 (Table S3). The precision of the method was determined as the percentage of the ratio of the standard deviation to the mean value (relative standard deviation, RSD) of the inter-day $(n=5)$ and intra-day $(n=5)$ analyses. The RSD $(\%)$ of the intra-day and inter-day precisions were in the range between $0.63-5.49$ and $0.95-4.48$, respectively. The precision results for each compound using the HPLC and CAK methods are presented in Supplementary Material 1 (Table S4). The effect of sample size (sample to solvent ratio) on the responses of the instruments was evaluated in two watermelon fruit samples for citrulline (see Supplementary Material 1, Figure S2). For HPLC analysis, a linear response was exhibited in the range of 25 to $500 \mathrm{mg}$ dry weight of watermelon fruit samples. The linearity of the responses using the Citrulline Assay Kit method was observed for a sample concentration of 10 to $75 \mathrm{mg}$ dry weight of watermelon fruit. Alcohols are commonly used for the extraction of citrulline and arginine instead of water. Ridwan et al. (2018) [28] and this study ensure the use of water with two different extraction and measurement methods. Other authors either simply thawed, diluted, centrifuged, or used the supernatant for analysis [11,23]. On the other hand, Hartman et al. (2019) [8] and Soteriou et al. (2017) [30] extracted the frozen samples in acidified solvent.

\subsubsection{Determination of Citrulline and Arginine Content Using HPLC}

A wide range of diversity in citrulline and arginine levels was exhibited by the investigated accessions and commercial varieties. The results are tabulated in Table 3. The average citrulline and arginine content in the entire genetic resources were 27.3 and $9.8 \mathrm{mg} / \mathrm{g}$, with ranges of 6.9 (S/No 12) to 52.1 (S/No 82) $\mathrm{mg} / \mathrm{g}$ and 1.8 (S/No 12) to 21.3 (S/No 100) $\mathrm{mg} / \mathrm{g}$, respectively. Previous reports indicated that citrulline levels ranged from 2.37 to $2.85 \mathrm{~g} / \mathrm{kg}$ fresh weight ( $\sim 33.8$ to $40.7 \mathrm{mg} / \mathrm{g}$, adjusted assuming 93\% water content in the flesh of watermelon fruit [2]) [8], 1.26 to $7.21 \mathrm{mg} / \mathrm{g}$ fresh weight ( 18.0 to $103 \mathrm{mg} / \mathrm{g}$ dry weight) [6,23], 11.25 to $14.74 \mathrm{mg} / \mathrm{g}$ [27], 5.7 to $28.8 \mathrm{mg} / \mathrm{g}$ [5], and 15.7 to $43.81 \mathrm{mg} / \mathrm{g}$ [28], while arginine concentrations ranged between 8.23 to $11.10 \mathrm{mg} / \mathrm{g}$ [8] and 1.32 to $1.47 \mathrm{~g} / \mathrm{kg}$ fresh weight ( 18.8 to $21.0 \mathrm{mg} / \mathrm{g}$ dry weight) [28]. These results are fairly in agreement with our report. All the genetic resources contained a higher level of citrulline compared to arginine, where citrulline was 1.27- to 7.68-fold higher. The highest combined concentrations of citrulline and arginine were detected in K192365 (S/No 82) and K192264 (S/No 75), which originated from Turkey and India, respectively, while the lowest concentration was detected in IT 190058 (S/No 12). Watermelon fruits that originated from Japan contained the highest average citrulline content followed by those from India. Indian originated fruits were superior in terms of the arginine content (see Figure 3 and Supplementary Material 2 (Figure S1) for photos). 


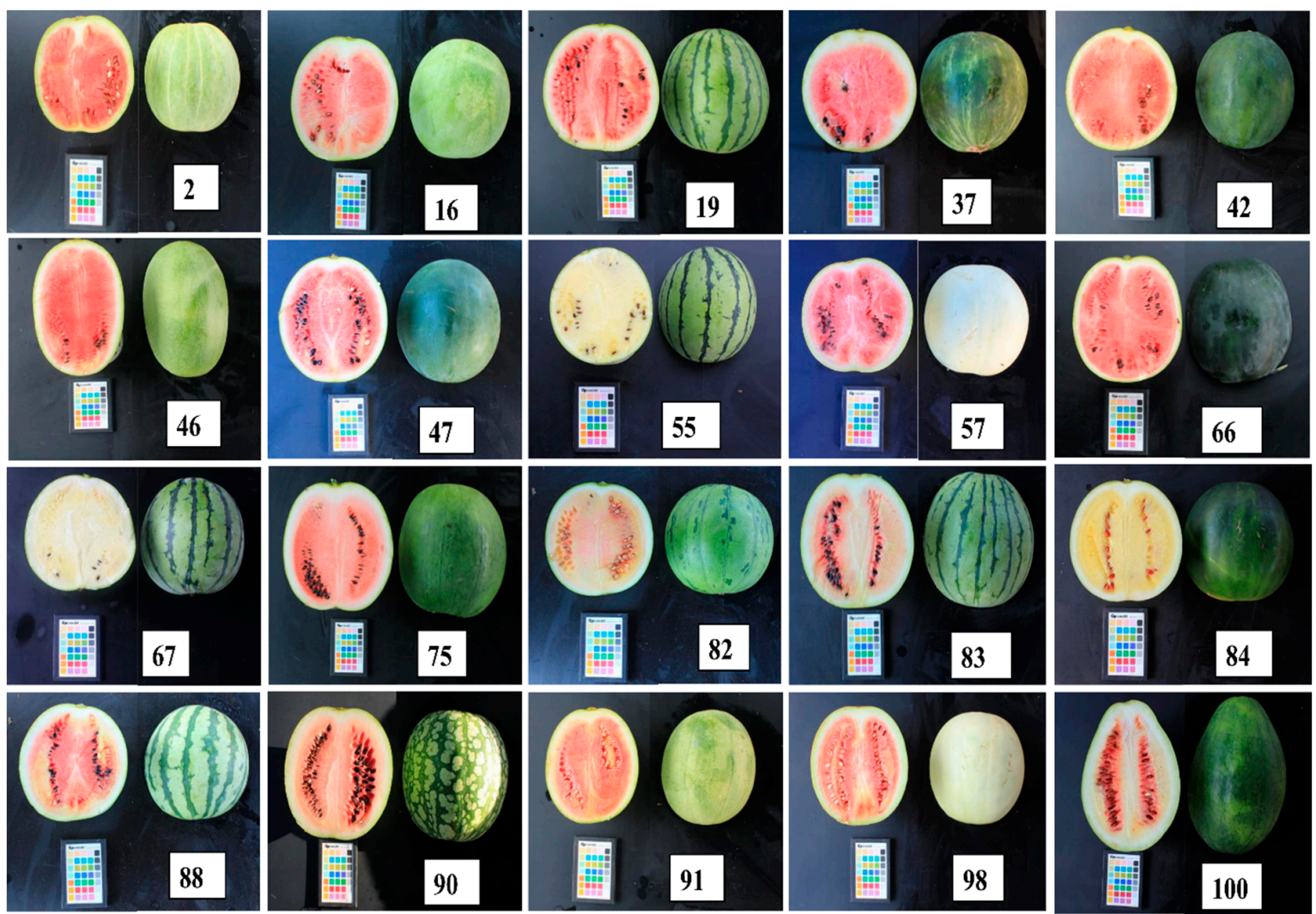

Figure 3. Representative photos of watermelon fruit samples exhibiting, relatively, the highest level of citrulline and arginine. The numbers in each photo correspond to S/No in Table 3.

Table 3. Citrulline and arginine contents (mg/g DW) in extracts of watermelon flesh samples using HPLC and the Citrulline Assay Kit.

\begin{tabular}{cccccc}
\hline S/No & Origin & $\begin{array}{c}\text { IT NO/ } \\
\text { Variety Name }\end{array}$ & Citrulline (HPLC) & Arginine (HPLC) & Citrulline (CAK) \\
\hline 1 & KOR & IT104713 & $22.85 \pm 1.67 \mathrm{i}-\mathrm{s}$ & $12.37 \pm 0.48 \mathrm{c}-\mathrm{m}$ & $26.39 \pm 0.69 \mathrm{e}-\mathrm{r}$ \\
2 & TUR & IT119709 & $44.30 \pm 0.49 \mathrm{ab}$ & $9.51 \pm 0.27 \mathrm{e}-\mathrm{q}$ & $39.54 \pm 0.54 \mathrm{a}-\mathrm{c}$ \\
3 & ITA & IT119743 & $30.03 \pm 0.06 \mathrm{c}-\mathrm{r}$ & $8.51 \pm 0.16 \mathrm{f}-\mathrm{r}$ & $28.46 \pm 0.70 \mathrm{c}-\mathrm{q}$ \\
4 & TWN & IT120006 & $28.52 \pm 2.01 \mathrm{c}-\mathrm{r}$ & $9.48 \pm 0.26 \mathrm{e}-\mathrm{q}$ & $25.23 \pm 0.35 \mathrm{f}-\mathrm{r}$ \\
5 & TWN & IT120008 & $27.16 \pm 0.48 \mathrm{~d}-\mathrm{s}$ & $11.64 \pm 0.18 \mathrm{c}-\mathrm{n}$ & $27.29 \pm 0.30 \mathrm{e}-\mathrm{q}$ \\
6 & Unknown & IT138188 & $22.26 \pm 0.39 \mathrm{i}-\mathrm{s}$ & $8.37 \pm 0.18 \mathrm{f}-\mathrm{r}$ & $23.46 \pm 0.45 \mathrm{~h}-\mathrm{r}$ \\
7 & CHN & IT160392 & $26.04 \pm 0.59 \mathrm{e}-\mathrm{s}$ & $7.62 \pm 0.32 \mathrm{~h}-\mathrm{s}$ & $29.42 \pm 0.24 \mathrm{c}-\mathrm{q}$ \\
8 & Unknown & IT174803 & $28.62 \pm 0.51 \mathrm{c}-\mathrm{r}$ & $6.34 \pm 0.09 \mathrm{~m}-\mathrm{s}$ & $26.75 \pm 0.20 \mathrm{e}-\mathrm{r}$ \\
9 & Unknown & IT185447 & $20.39 \pm 0.42 \mathrm{l}-\mathrm{s}$ & $6.61 \pm 0.36 \mathrm{~m}-\mathrm{s}$ & $21.76 \pm 0.15 \mathrm{j}-\mathrm{r}$ \\
10 & Unknown & IT185456 & $18.10 \pm 0.17 \mathrm{p}-\mathrm{t}$ & $4.39 \pm 0.34 \mathrm{p}-\mathrm{s}$ & $19.72 \pm 0.20 \mathrm{o}-\mathrm{r}$ \\
11 & USA & IT190057 & $21.92 \pm 0.63 \mathrm{j}-\mathrm{s}$ & $12.18 \pm 0.12 \mathrm{c}-\mathrm{m}$ & $22.57 \pm 0.25 \mathrm{~h}-\mathrm{r}$ \\
12 & USA & IT190058 & $6.90 \pm 0.12 \mathrm{t}$ & $1.76 \pm 0.19 \mathrm{~s}$ & $6.54 \pm 0.28 \mathrm{~s}$ \\
13 & UKR & IT190059 & $25.22 \pm 0.53 \mathrm{~g}-\mathrm{s}$ & $14.39 \pm 0.33 \mathrm{c}-\mathrm{g}$ & $23.64 \pm 0.30 \mathrm{~h}-\mathrm{r}$ \\
14 & TKM & IT190077 & $21.52 \pm 0.26 \mathrm{j}-\mathrm{s}$ & $11.54 \pm 0.31 \mathrm{c}-\mathrm{n}$ & $20.19 \pm 0.11 \mathrm{n}-\mathrm{r}$ \\
15 & KGZ & IT190084 & $29.17 \pm 1.30 \mathrm{c}-\mathrm{r}$ & $9.59 \pm 0.3 \mathrm{e}-\mathrm{q}$ & $24.99 \pm 0.59 \mathrm{~g}-\mathrm{r}$ \\
16 & TJK & IT190110 & $33.45 \pm 0.98 \mathrm{~b}-\mathrm{n}$ & $13.50 \pm 0.43 \mathrm{c}-\mathrm{j}$ & $32.51 \pm 0.16 \mathrm{a}-\mathrm{j}$ \\
17 & TJK & IT190116 & $23.51 \pm 0.17 \mathrm{i}-\mathrm{s}$ & $10.74 \pm 0.18 \mathrm{~d}-\mathrm{p}$ & $23.50 \pm 0.51 \mathrm{~h}-\mathrm{r}$ \\
18 & KAZ & IT190123 & $25.96 \pm 0.43 \mathrm{e}-\mathrm{s}$ & $7.66 \pm 0.22 \mathrm{~h}-\mathrm{s}$ & $28.22 \pm 0.06 \mathrm{~d}-\mathrm{q}$ \\
19 & TKM & IT190135 & $33.46 \pm 1.29 \mathrm{~b}-\mathrm{n}$ & $12.39 \pm 0.18 \mathrm{c}-\mathrm{m}$ & $31.98 \pm 0.72 \mathrm{~b}-\mathrm{l}$ \\
20 & BRA & IT190141 & $26.63 \pm 0.73 \mathrm{e}-\mathrm{s}$ & $6.36 \pm 0.1 \mathrm{~m}-\mathrm{s}$ & $27.45 \pm 0.20 \mathrm{~d}-\mathrm{q}$ \\
21 & RUS & IT190146 & $23.54 \pm 0.66 \mathrm{i}-\mathrm{s}$ & $6.47 \pm 0.191 \mathrm{-s}$ & $25.10 \pm 0.69 \mathrm{~g}-\mathrm{r}$ \\
22 & RUS & IT190148 & $19.31 \pm 0.51 \mathrm{o}-\mathrm{s}$ & $8.47 \pm 0.08 \mathrm{f}-\mathrm{r}$ & $21.51 \pm 0.47 \mathrm{j}-\mathrm{r}$ \\
23 & Unknown & IT190151 & $26.54 \pm 0.76 \mathrm{e}-\mathrm{s}$ & $11.81 \pm 0.14 \mathrm{c}-\mathrm{n}$ & $26.24 \pm 0.39 \mathrm{e}-\mathrm{r}$ \\
24 & RUS & IT199769 & $31.47 \pm 0.24 \mathrm{~b}-\mathrm{p}$ & $11.96 \pm 0.04 \mathrm{c}-\mathrm{n}$ & $28.79 \pm 0.50 \mathrm{c}-\mathrm{q}$ \\
\hline
\end{tabular}


Table 3. Cont.

\begin{tabular}{|c|c|c|c|c|c|}
\hline S/No & Origin & $\begin{array}{c}\text { IT NO/ } \\
\text { Variety Name }\end{array}$ & Citrulline (HPLC) & Arginine (HPLC) & Citrulline (CAK) \\
\hline 25 & RUS & IT199772 & $29.22 \pm 0.58 c-r$ & $8.37 \pm 0.18 \mathrm{f}-\mathrm{r}$ & $27.45 \pm 0.32 \mathrm{~d}-\mathrm{q}$ \\
\hline 26 & RUS & IT199773 & $20.57 \pm 0.571-\mathrm{s}$ & $10.07 \pm 0.19 \mathrm{~d}-\mathrm{q}$ & $20.84 \pm 0.101-r^{1}$ \\
\hline 27 & RUS & IT199788 & $33.00 \pm 0.38 \mathrm{~b}-\mathrm{O}$ & $6.76 \pm 0.18 \mathrm{k}-\mathrm{s}$ & $31.23 \pm 0.51 c-n$ \\
\hline 28 & RUS & IT199796 & $24.75 \pm 0.75 \mathrm{~g}-\mathrm{s}$ & $8.56 \pm 0.2 \mathrm{f}-\mathrm{r}$ & $26.89 \pm 0.45$ e-r \\
\hline 29 & UKR & IT199805 & $20.76 \pm 0.41 \mathrm{k}-\mathrm{s}$ & $6.52 \pm 0.311-\mathrm{s}$ & $22.56 \pm 0.38 \mathrm{~h}-\mathrm{r}$ \\
\hline 30 & UKR & IT199806 & $21.80 \pm 0.80 \mathrm{j}-\mathrm{s}$ & $8.53 \pm 0.33 \mathrm{f}-\mathrm{r}$ & $26.55 \pm 0.36 \mathrm{e}-\mathrm{r}$ \\
\hline 31 & KAZ & IT199814 & $25.83 \pm 0.43 \mathrm{f}-\mathrm{s}$ & $8.89 \pm 0.18$ e-r & $27.30 \pm 0.17 \mathrm{e}-\mathrm{q}$ \\
\hline 32 & UZB & IT199823 & $24.65 \pm 0.48 \mathrm{~g}-\mathrm{s}$ & $8.34 \pm 0.05 \mathrm{f}-\mathrm{r}$ & $26.50 \pm 0.32 \mathrm{e}-\mathrm{r}$ \\
\hline 33 & NPL & IT200493 & $28.08 \pm 0.15 c-r$ & $7.53 \pm 0.24 \mathrm{~h}-\mathrm{s}$ & $25.58 \pm 0.52 \mathrm{e}-\mathrm{r}$ \\
\hline 34 & PHL & IT201722 & $29.63 \pm 0.51 \mathrm{c}-\mathrm{r}$ & $9.50 \pm 0.36 \mathrm{e}-\mathrm{q}$ & $28.51 \pm 0.39 c-q$ \\
\hline 35 & UZB & IT202998 & $19.65 \pm 0.20 \mathrm{n}-\mathrm{s}$ & $8.61 \pm 0.12 \mathrm{f}-\mathrm{r}$ & $21.76 \pm 0.48 \mathrm{j}-\mathrm{r}^{1}$ \\
\hline 36 & RUS & IT203017 & $26.38 \pm 0.30 \mathrm{e}-\mathrm{s}$ & $10.14 \pm 0.12 \mathrm{~d}-\mathrm{q}$ & $25.79 \pm 0.08 \mathrm{e}-\mathrm{r}$ \\
\hline 37 & RUS & IT203019 & $34.73 \pm 0.62 \mathrm{~b}-\mathrm{k}$ & $11.61 \pm 0.41 c-n$ & $32.04 \pm 0.63 \mathrm{~b}-1$ \\
\hline 38 & KAZ & IT203029 & $24.01 \pm 0.52 \mathrm{i}-\mathrm{s}$ & $9.07 \pm 0.05 \mathrm{e}-\mathrm{q}$ & $33.81 \pm 0.08 \mathrm{a}-\mathrm{h}$ \\
\hline 39 & UZB & IT203034 & $26.09 \pm 1.55 \mathrm{e}-\mathrm{s}$ & $8.87 \pm 0.03$ e-r & $26.55 \pm 0.91 \mathrm{e}-\mathrm{r}$ \\
\hline 40 & RUS & IT203037 & $30.32 \pm 0.49 c-q$ & $10.24 \pm 0.11 \mathrm{~d}-\mathrm{q}$ & $27.28 \pm 0.20 \mathrm{e}-\mathrm{q}$ \\
\hline 41 & UZB & IT203049 & $31.44 \pm 2.27 b-p$ & $7.36 \pm 0.37 \mathrm{i}-\mathrm{s}$ & $31.32 \pm 0.29 c-n$ \\
\hline 42 & UZB & IT203067 & $34.11 \pm 2.50 \mathrm{~b}-1$ & $10.78 \pm 0.11 \mathrm{~d}-\mathrm{p}$ & $35.26 \pm 0.26 \mathrm{a}-\mathrm{g}$ \\
\hline 43 & AZE & IT203072 & $31.82 \pm 3.32 b-p$ & $9.60 \pm 0.07 \mathrm{e}-\mathrm{q}$ & $32.48 \pm 0.38 \mathrm{a}-\mathrm{k}$ \\
\hline 44 & Unknown & IT203627 & $32.79 \pm 0.45 b-0$ & $11.40 \pm 0.35 c-n$ & $29.34 \pm 0.19 c-q$ \\
\hline 45 & MNG & IT204167 & $25.98 \pm 1.18 \mathrm{e}-\mathrm{s}$ & $11.53 \pm 0.11 c-n$ & $25.81 \pm 0.58 \mathrm{e}-\mathrm{r}$ \\
\hline 46 & Unknown & IT208441 & $30.10 \pm 1.30 \mathrm{c}-\mathrm{r}$ & $15.28 \pm 0.3 \mathrm{bcde}$ & $30.39 \pm 0.51 c-p$ \\
\hline 47 & UZB & IT213903 & $33.22 \pm 1.88 \mathrm{~b}-\mathrm{o}$ & $16.50 \pm 0.18 \mathrm{abcd}$ & $31.01 \pm 0.24 \mathrm{c}-\mathrm{O}$ \\
\hline 48 & Unknown & IT216860 & $21.20 \pm 2.83 \mathrm{j}-\mathrm{s}$ & $9.13 \pm 0.36 \mathrm{e}-\mathrm{q}$ & $21.57 \pm 0.24$ j-r \\
\hline 49 & Unknown & IT251845 & $33.38 \pm 1.62 b-n$ & $9.36 \pm 0.48 \mathrm{e}-\mathrm{q}$ & $32.59 \pm 0.39 a-j$ \\
\hline 50 & Unknown & IT251849 & $34.91 \pm 1.48 \mathrm{~b}-\mathrm{j}$ & $8.66 \pm 0.31 \mathrm{f}-\mathrm{r}$ & $31.23 \pm 0.52 c-n$ \\
\hline 51 & Unknown & IT251851 & $23.08 \pm 0.93 \mathrm{i}-\mathrm{s}$ & $7.38 \pm 0.14 \mathrm{i}-\mathrm{s}$ & $23.48 \pm 0.34 \mathrm{~h}-\mathrm{r}$ \\
\hline 52 & RUS & IT251860 & $35.95 \pm 2.25 \mathrm{~b}-\mathrm{i}$ & $7.52 \pm 0.12 \mathrm{~h}-\mathrm{s}$ & $31.60 \pm 0.36 \mathrm{~b}-\mathrm{m}$ \\
\hline 53 & USA & IT271064 & $20.89 \pm 1.09 \mathrm{k}-\mathrm{s}$ & $7.34 \pm 0.18 \mathrm{j}-\mathrm{s}$ & $20.54 \pm 0.09 \mathrm{~m}-\mathrm{r}$ \\
\hline 54 & $\mathrm{CHN}$ & IT294452 & $24.85 \pm 1.61 \mathrm{~g}-\mathrm{s}$ & $5.58 \pm 0.36 \mathrm{n}-\mathrm{s}$ & $23.46 \pm 0.56 \mathrm{~h}-\mathrm{r}$ \\
\hline 55 & JPN & IT302244 & $39.30 \pm 0.84 \mathrm{~b}-\mathrm{f}$ & $9.12 \pm 0.22 \mathrm{e}-\mathrm{q}$ & $36.74 \pm 0.54$ a-e \\
\hline 56 & UZB & IT305108 & $26.65 \pm 1.63 \mathrm{e}-\mathrm{s}$ & $13.98 \pm 0.05 c-h$ & $24.53 \pm 0.19$ g-r \\
\hline 57 & RUS & IT321060 & $32.52 \pm 1.86 \mathrm{~b}-\mathrm{o}$ & $12.97 \pm 0.15 c-1$ & $33.53 \pm 0.39 \mathrm{a}-\mathrm{i}$ \\
\hline 58 & UZB & IT321075 & $24.79 \pm 1.53 \mathrm{~g}-\mathrm{s}$ & $8.52 \pm 0.10 \mathrm{f}-\mathrm{r}$ & $22.61 \pm 0.49 \mathrm{~h}-\mathrm{r}$ \\
\hline 59 & Unknown & IT32839 & $23.09 \pm 0.45 \mathrm{i}-\mathrm{s}$ & $4.70 \pm 0.21 \mathrm{o}-\mathrm{s}$ & $21.11 \pm 0.62 \mathrm{k}-\mathrm{r}$ \\
\hline 60 & URY & IT119741 & $16.94 \pm 0.42 \mathrm{q}-\mathrm{t}$ & $6.37 \pm 0.23 \mathrm{~m}-\mathrm{s}$ & $22.47 \pm 0.71 \mathrm{~h}-\mathrm{r}$ \\
\hline 61 & RUS & IT199776 & $31.57 \pm 2.04 b-p$ & $9.80 \pm 0.03 \mathrm{e}-\mathrm{q}$ & $31.09 \pm 0.37 \mathrm{c}-\mathrm{o}$ \\
\hline 62 & RUS & IT199783 & $27.11 \pm 3.47 \mathrm{~d}-\mathrm{s}$ & $14.90 \pm 0.08 \mathrm{c}-\mathrm{f}$ & $28.15 \pm 0.32 \mathrm{~d}-\mathrm{q}$ \\
\hline 63 & UKR & IT199804 & $14.00 \pm 0.22 \mathrm{st}$ & $9.69 \pm 0.19 \mathrm{e}-\mathrm{q}$ & $15.75 \pm 0.20 \mathrm{r}$ \\
\hline 64 & USA & IT199834 & $25.91 \pm 0.98 \mathrm{f}-\mathrm{s}$ & $13.93 \pm 0.26 \mathrm{c}-\mathrm{i}$ & $23.2 \pm 0.52 \mathrm{~h}-\mathrm{r}$ \\
\hline 65 & $\mathrm{CHN}$ & 803617 & $26.82 \pm 0.70 \mathrm{~d}-\mathrm{s}$ & $8.42 \pm 0.18 \mathrm{f}-\mathrm{r}$ & $26.13 \pm 0.54 \mathrm{e}-\mathrm{r}$ \\
\hline 66 & RUS & 805656 & $28.20 \pm 0.60 c-r$ & $17.48 \pm 0.21 \mathrm{a}-\mathrm{c}$ & $26.35 \pm 0.34$ e-r \\
\hline 67 & JPN & 807364 & $41.38 \pm 2.12 \mathrm{a}-\mathrm{c}$ & $6.63 \pm 0.391-\mathrm{s}$ & $35.81 \pm 1.00 \mathrm{a}-\mathrm{g}$ \\
\hline 68 & KOR & 906976 & $22.90 \pm 0.90 \mathrm{i}-\mathrm{s}$ & $9.94 \pm 0.02 \mathrm{e}-\mathrm{q}$ & $21.04 \pm 0.441-\mathrm{r}$ \\
\hline 69 & Unknown & 908581 & $24.79 \pm 0.93 \mathrm{~g}-\mathrm{s}$ & $8.48 \pm 0.11 \mathrm{f}-\mathrm{r}$ & $22.75 \pm 0.58 \mathrm{~h}-\mathrm{r}$ \\
\hline 70 & UZB & 908835 & $22.02 \pm 1.38 \mathrm{i}-\mathrm{s}$ & $13.41 \pm 0.11 c-j$ & $20.42 \pm 0.29 \mathrm{~m}-\mathrm{r}$ \\
\hline 71 & Unknown & K004668 & $26.78 \pm 1.18 \mathrm{~d}-\mathrm{s}$ & $12.13 \pm 0.08 c-n$ & $25.69 \pm 0.40 \mathrm{e}-\mathrm{r}$ \\
\hline 72 & USA & K012424 & $28.67 \pm 1.14 \mathrm{c}-\mathrm{r}$ & $11.00 \pm 0.29 \mathrm{~d}-\mathrm{o}$ & $28.54 \pm 0.26 \mathrm{c}-\mathrm{q}$ \\
\hline 73 & KOR & K038117 & $24.05 \pm 0.67 \mathrm{i}-\mathrm{s}$ & $8.44 \pm 0.12 \mathrm{f}-\mathrm{r}$ & $21.33 \pm 0.46 \mathrm{j}-\mathrm{r}^{1}$ \\
\hline 74 & IND & K192260 & $29.26 \pm 1.62 \mathrm{c}-\mathrm{r}$ & $11.74 \pm 0.14 c-n$ & $29.85 \pm 0.36 c-q$ \\
\hline 75 & IND & K192264 & $38.19 \pm 0.67 b-h$ & $20.69 \pm 0.23 \mathrm{ab}$ & $42.06 \pm 0.29 \mathrm{ab}$ \\
\hline 76 & TUR & K192296 & $19.91 \pm 0.54 \mathrm{~m}-\mathrm{s}$ & $9.70 \pm 0.15 \mathrm{e}-\mathrm{q}$ & $20.97 \pm 0.311-r$ \\
\hline 77 & TUR & K192319 & $26.98 \pm 0.64 \mathrm{~d}-\mathrm{s}$ & $7.56 \pm 0.21 \mathrm{~h}-\mathrm{s}$ & $25.94 \pm 0.52 \mathrm{e}-\mathrm{r}$ \\
\hline 78 & TUR & K192321 & $30.68 \pm 0.70 c-q$ & $8.45 \pm 0.35 \mathrm{f}-\mathrm{r}$ & $30.89 \pm 0.74 c-p$ \\
\hline 79 & TUR & K192324 & $25.02 \pm 0.68 \mathrm{~g}-\mathrm{s}$ & $11.37 \pm 0.23 c-n$ & $27.83 \pm 0.82 \mathrm{~d}-\mathrm{q}$ \\
\hline 80 & TUR & K192338 & $22.53 \pm 0.54 \mathrm{i}-\mathrm{s}$ & $12.33 \pm 0.15 \mathrm{c}-\mathrm{m}$ & $23.69 \pm 0.62 \mathrm{~h}-\mathrm{r}$ \\
\hline 81 & TUR & K192352 & $26.08 \pm 0.38$ e-s & $7.87 \pm 0.19 \mathrm{~g}-\mathrm{s}$ & $25.40 \pm 0.25 \mathrm{f}-\mathrm{r}$ \\
\hline
\end{tabular}


Table 3. Cont.

\begin{tabular}{|c|c|c|c|c|c|}
\hline S/No & Origin & $\begin{array}{c}\text { IT NO/ } \\
\text { Variety Name }\end{array}$ & Citrulline (HPLC) & Arginine (HPLC) & Citrulline (CAK) \\
\hline 82 & TUR & K192365 & $52.06 \pm 0.59 a$ & $8.46 \pm 0.20 \mathrm{f}-\mathrm{r}$ & $42.79 \pm 0.48 a$ \\
\hline 83 & TUR & K192370 & $40.53 \pm 0.51 \mathrm{~b}-\mathrm{d}$ & $12.25 \pm 0.33 \mathrm{c}-\mathrm{m}$ & $36.51 \pm 0.46 \mathrm{a}-\mathrm{f}$ \\
\hline 84 & TUR & K192373 & $32.36 \pm 0.34 \mathrm{~b}-\mathrm{o}$ & $13.26 \pm 0.30 \mathrm{c}-\mathrm{k}$ & $29.78 \pm 0.29 c-q$ \\
\hline 85 & TUR & K192378 & $28.84 \pm 0.30 \mathrm{c}-\mathrm{r}$ & $11.10 \pm 0.07 \mathrm{c}-\mathrm{o}$ & $24.97 \pm 0.66$ g-r \\
\hline 86 & TUR & K192379 & $24.51 \pm 1.04 \mathrm{~h}-\mathrm{s}$ & $10.45 \pm 0.15 \mathrm{~d}-\mathrm{p}$ & $22.08 \pm 0.23 \mathrm{j}-\mathrm{r}$ \\
\hline 87 & TUR & K192381 & $28.33 \pm 0.47 \mathrm{c}-\mathrm{r}$ & $10.43 \pm 0.18 \mathrm{~d}-\mathrm{p}$ & $26.02 \pm 0.18$ e-r \\
\hline 88 & TUR & K192386 & $38.42 \pm 0.86 \mathrm{~b}-\mathrm{g}$ & $10.00 \pm 0.18 \mathrm{e}-\mathrm{q}$ & $35.47 \pm 0.30 \mathrm{a}-\mathrm{g}$ \\
\hline 89 & TUR & K192390 & $33.35 \pm 0.58 b-n$ & $8.57 \pm 0.20 \mathrm{f}-\mathrm{r}$ & $30.07 \pm 0.61 c-p$ \\
\hline 90 & TUR & K192394 & $39.76 \pm 0.87$ b-e & $7.84 \pm 0.13 \mathrm{~g}-\mathrm{s}$ & $38.56 \pm 0.28 \mathrm{a}-\mathrm{d}$ \\
\hline 91 & TUR & K192397 & $33.05 \pm 0.09 \mathrm{~b}-\mathrm{o}$ & $11.82 \pm 0.04 c-n$ & $29.02 \pm 0.09 c-q$ \\
\hline 92 & TUR & K192403 & $26.51 \pm 0.84 \mathrm{e}-\mathrm{s}$ & $12.39 \pm 0.36 \mathrm{c}-\mathrm{m}$ & $25.60 \pm 0.52$ e-r \\
\hline 93 & TUR & K192432 & $19.80 \pm 0.53 \mathrm{n}-\mathrm{s}$ & $7.54 \pm 0.24$ h-s & $22.67 \pm 0.45 \mathrm{~h}-\mathrm{r}$ \\
\hline 94 & TUR & K192444 & $25.04 \pm 0.54 \mathrm{~g}-\mathrm{s}$ & $9.24 \pm 0.06 \mathrm{e}-\mathrm{q}$ & $25.64 \pm 0.27$ e-r \\
\hline 95 & TUR & K192446 & $33.79 \pm 0.36 \mathrm{~b}-\mathrm{m}$ & $6.50 \pm 0.351-\mathrm{s}$ & $30.68 \pm 0.36 c-p$ \\
\hline 96 & TUR & K192467 & $33.03 \pm 0.42 b-o$ & $7.56 \pm 0.33 \mathrm{~h}-\mathrm{s}$ & $31.21 \pm 0.60 c-n$ \\
\hline 97 & TUR & K192469 & $25.41 \pm 0.45 \mathrm{~g}-\mathrm{s}$ & $8.89 \pm 0.22$ e-r & $25.78 \pm 0.22 \mathrm{e}-\mathrm{r}$ \\
\hline 98 & IRQ & K192471 & $31.14 \pm 0.46 \mathrm{~b}-\mathrm{p}$ & $13.81 \pm 0.26 c-j$ & $28.95 \pm 0.94 c-q$ \\
\hline 99 & TUR & K192502 & $16.19 \pm 0.61 \mathrm{r}-\mathrm{t}$ & $3.82 \pm 0.25 \mathrm{q}-\mathrm{s}$ & $18.57 \pm 0.38 \mathrm{qr}$ \\
\hline 100 & TUR & K192504 & $26.91 \pm 0.34 \mathrm{~d}-\mathrm{s}$ & $21.25 \pm 0.11 \mathrm{a}$ & $28.26 \pm 0.51 \mathrm{~d}-\mathrm{q}$ \\
\hline 101 & KOR & Speedggul & $22.07 \pm 0.78 \mathrm{i}-\mathrm{s}$ & $8.50 \pm 0.19 \mathrm{f}-\mathrm{r}$ & $25.23 \pm 0.40 \mathrm{f}-\mathrm{r}$ \\
\hline 102 & KOR & Sambokggul & $25.70 \pm 0.23 \mathrm{f}-\mathrm{s}$ & $8.44 \pm 0.15 \mathrm{f}-\mathrm{r}$ & $29.67 \pm 0.22 c-q$ \\
\hline 103 & KOR & Seo Tae Ja & $24.58 \pm 0.86 \mathrm{~g}-\mathrm{s}$ & $9.39 \pm 0.31 \mathrm{e}-\mathrm{q}$ & $26.53 \pm 0.33$ e-r \\
\hline 104 & KOR & Uriggul & $23.88 \pm 0.47 \mathrm{i}-\mathrm{s}$ & $10.61 \pm 0.35 \mathrm{~d}-\mathrm{p}$ & $28.85 \pm 0.52 \mathrm{c}-\mathrm{q}$ \\
\hline 105 & KOR & Newkkokkoma & $19.50 \pm 0.43 n-s$ & $2.54 \pm 0.03 \mathrm{rs}$ & $19.62 \pm 0.34$ p-r \\
\hline 106 & KOR & Lycofreshi & $18.33 \pm 0.31 \mathrm{p}-\mathrm{t}$ & $9.39 \pm 0.13 \mathrm{e}-\mathrm{q}$ & $22.35 \pm 0.35 \mathrm{i}-\mathrm{r}$ \\
\hline 107 & KOR & Norangsambokggul & $23.85 \pm 0.95 \mathrm{i}-\mathrm{s}$ & $11.46 \pm 0.2 c-n$ & $30.13 \pm 0.56 c-p$ \\
\hline
\end{tabular}

$\mathrm{S} / \mathrm{No}=$ Sample identification number; Different letters between rows indicate statistically significant differences between watermelon genetic resources at $p<0.05$.

In an attempt to group the genetic resources based on the levels of citrulline and arginine, and to examine the effect of flesh color on those phytonutrients, Principal Component Analysis (PCA) was conducted (Figures 4 and 5; Supplementary Material 1, Table S5). The first two principal components contributed to 69.3 and $27.8 \%$ of the variation, with citrulline and arginine contributing the most for the first and second principal components, respectively. As can be seen in the scatter plots, the genetic resources were distributed homogeneously throughout the four quadrants with no significant groupings; however, some of the samples (S/No 12, 82, 100,75) were seen to be well-separated from each other and from the entire population. This could be due to the exceptionally low levels of arginine and citrulline in S/No 12, high level of citrulline in S/No 82, high level of arginine in S/No 100, and high levels of arginine and citrulline in S/No 75.

Most of the fruit morphological characteristics did not have an effect on the level of citrulline and arginine. The fruit width and length had a moderate negative effect on the citrulline level, with shorter and narrower accessions exhibiting higher citrulline levels. However, there was no significant correlation between arginine and fruit length and width. Fruit samples with shorter widths of stripes had a higher arginine level(Table 2). When averaged for all colors, orange $(35.6 \mathrm{mg} / \mathrm{g}$ ) and yellow $(31.5 \mathrm{mg} / \mathrm{g})$ colored flesh watermelon fruit samples contained slightly higher citrulline levels compared to pink $(27.9 \mathrm{mg} / \mathrm{g})$, pink/red $(25.9 \mathrm{mg} / \mathrm{g})$, and red $(27.0 \mathrm{mg} / \mathrm{g})$. However, arginine levels were not associated with the flesh color. Conflicting results were reported previously. Davis et al. (2011) [23] and Wehner et al. (2017) [26] reported the absence of association between citrulline levels and flesh color, whereas less citrulline content was detected in red-fleshed melons compared to yellow according to Rimando and Perkins-Veazie (2005) [5]. The SSC had a negative significant effect $(p<0.01)$ on both citrulline and arginine concentrations (Table 2). The negative correlations of citrulline, arginine, and citrulline + arginine with SSC observed in this study are concurrent with Hartman et al. (2019) [8], 
but contradict Wehner et al. (2017) [26]. A positive significant correlation $(p<0.01)$ was observed between citrulline and arginine, which could be because the former is the precursor of the latter.

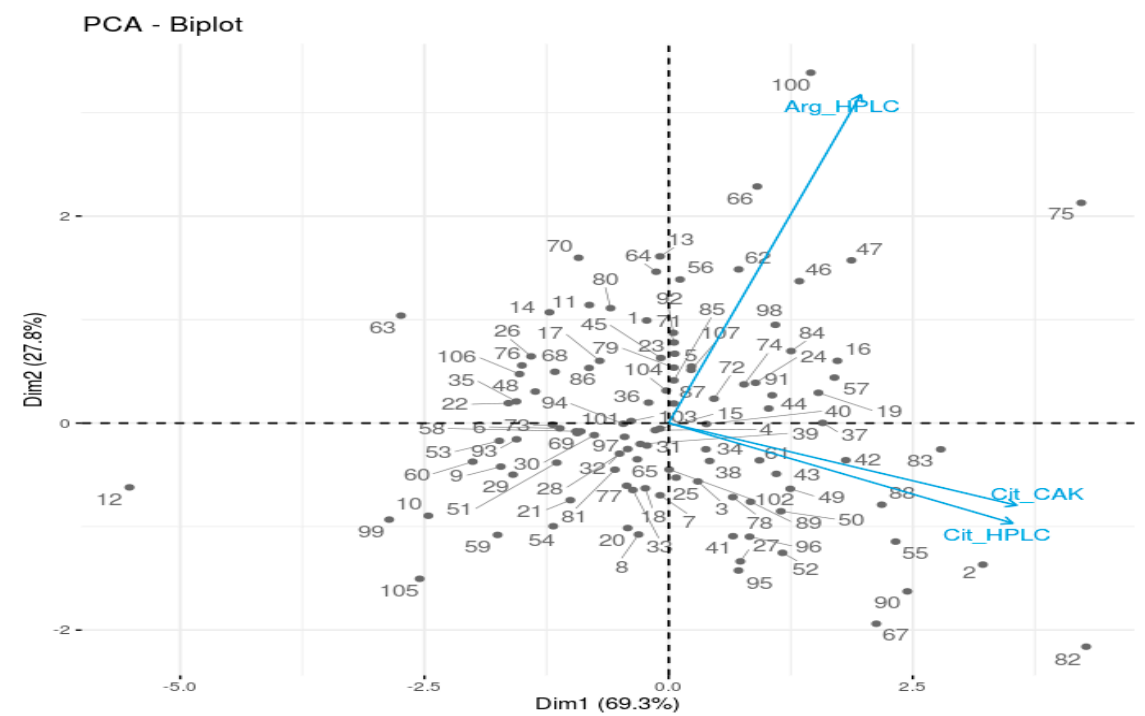

Figure 4. PCA-Biplot of watermelon fruit samples with citrulline and arginine as individual parameters (Arg_HPLC and Cit_HPLC represents arginine and citrulline contents determined using HPLC method); Cit_CAK is the citrulline content measured using the Citrulline Assay Kit method.

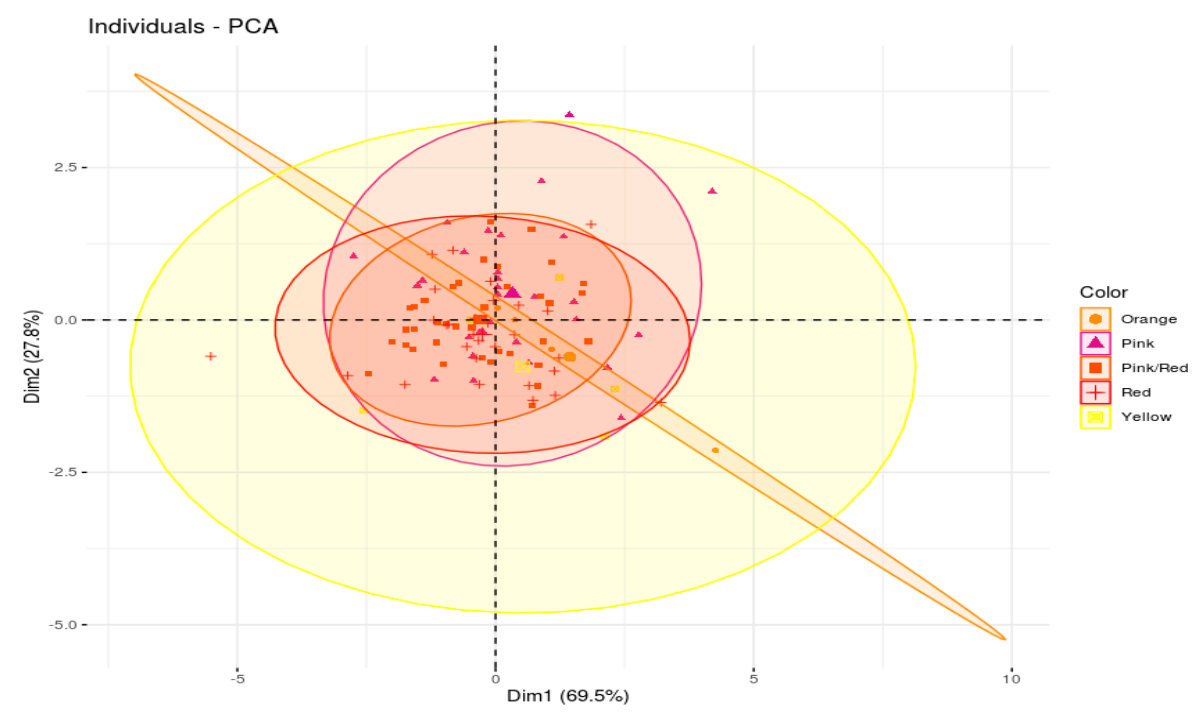

Figure 5. PCA-individual plot of watermelon fruit samples generated according to fruit flesh color.

The levels of citrulline and arginine in watermelon were reported to be affected by genotypes, cultivar, ploidy, flesh color, fruit anatomy, fruit ripeness, sample treatment methods, nitrogen status, salt tolerance, and environmental factors such as drought and light stress [5,7,8,10,31-34]. However, Davis et al. (2011) [23] ruled out the effect of some properties such as flesh color, fruit size and shape, skin color or pattern, fruit earliness, or soluble solids content on citrulline content in a study involving 56 watermelon cultivars, breeding lines, and PI accessions. These conflicting reports aside, the citrulline level in watermelon fruit is regulated by others factors such as genotypes, plant part, fruit development, nitrogen level, and stress. Previous reports indicated that watermelon fruit peel, an underutilized agricultural waste, is a rich source of citrulline compared to the edible flesh tissue, unlike arginine $[7,28]$. Citrulline is involved in maintaining the osmolarity of cells during abiotic stress, allowing watermelon to accumulate high levels of citrulline in response to oxidative stress caused by drastic conditions $[10,33]$. The accumulation of a higher level of citrulline in the peel could be due to the more stress it could 
experience relative to the central portion of the flesh and inner rinds. This could provide an insight into the source of variations of citrulline and arginine between different tissues. Transcriptomic analysis could help to understand the regulation of the genes associated with citrulline and arginine metabolism. To the best of our knowledge, no studies have been done to find out how genetic variability impacts the citrulline metabolism. In this study, the extraction and analysis of citrulline and arginine were conducted based on previously optimized methods for watermelon fruit $[8,27,28]$, with some modifications such as extraction solvent. Citrulline and arginine could be better extracted using more environmentally benign solvents like water instead of organic solvents [28]. The nitrogen status of the plant regulates the citrulline level, where nitrogen deficiency causes a decrease in citrulline level [33]. The growth of watermelon in this study was maintained with an optimum addition of fertilizer as per the RDA's agricultural management practices. Other factors that could impact the recovery of citrulline and arginine, such as sample size and particle size, were also optimized using citrulline to obtain the highest yield. As maturity impacts the levels of citrulline and arginine, watermelon fruits were harvested at full ripeness when their concentration peaks.

One way to improve watermelon fruit quality is through knowledge of the commulative effects of genotypic, physiological, and agroenvironmental factors. So far, signifcant advancements have been made on characterizing several factors of fruit quality. A study on a diverse genetic resources across the word could help to advance our current knowlege of watermelon fruit and its quality traits. Citrulline and arginine are important phytonutrients not only for the wellbeing of human health, but also for various metabolic processes taking place in plants, including watermelon. Since citrulline and arginine accumulation is affected by various factors, as discussed above, these compounds might be considered for assessing and screening watermelon genotypes as well as novel biochemical indicators in breeding programs. An increased citrulline and arginine content in watermelon could enhance tolerance of watermelon plants towards drought. Breeding could improve the levels of arginine in watermelon fruit, as both are heritable traits [26,35]. Because of the intensification of the demand for high yielding, diseases resistant, and highly nutritive food crops, including watermelon, the conservation and collection of genetically diverse genetic resources are essential activities for the maintenance and improvement of the current level of production.

\subsubsection{Quantification of Citrulline Using Citrulline Assay Kit}

The Citrulline Assay Kit (CAK) is a simple colorimetric assay that measures the amount of total citrulline present in biological samples such as cells, tissue, plasma serum, or urine samples [36-38]. Watermelon tissue sample extracts were treated with sodium dodecyl sulfate (SDS) and proteinase K to release free citrulline residues, followed by the addition of assay reagents (assay reagents $\mathrm{A}$ and B). The reaction of assay reagents with the released free citrulline at $95^{\circ} \mathrm{C}$ produces chromophore that absorbs UV light at 540-560 nm. Studies on the citrulline levels of watermelon and other plant materials using a Citrulline Assay Kit are elusive. To the best of our knowledge, this is the first report on watermelon flesh samples. The citrulline content determined with this method ranged from 6.5 (S/No 12) to 42.8 (S/No 82) $\mathrm{mg} / \mathrm{g}$ with a population mean of $27.0 \mathrm{mg} / \mathrm{g}$ (Table 3). The concentrations of citrulline measured using HPLC and the Citrulline Assay Kit showed a significant correlation with each other $\left(r^{2}=0.919 ; p<0.01\right)$ and a 0.71- to 1.22-fold difference between each sample measurements among the two methods. The population means in the two methods (Citrulline Assay Kit and HPLC) are almost similar ( 27.0 and $27.3 \mathrm{mg} / \mathrm{g}$, respectively). Colorimetric methods for the quantification of citrulline that is developed earlier [39] could overestimate the actual citrulline levels, and in thin layer chromatography and amino acid analyzers, the presence of glutamine could complicate quantification $[6,23]$. Other colorimetric citrulline analysis methods that have been mainly developed for animal and human tissues use strong oxidizers to hydrolyze tissues completely [40-42]. These strong sample treatments could cause the oxidation of citrulline in watermelon tissues and result in erroneously low values. The Citrulline Assay Kit method used in our study gave citrulline concentrations in the same general range as HPLC, which was adequate for estimating citrulline in order to compare a 
set of watermelon samples with another set of watermelon samples. The CAK is simple, efficient, and convenient to use for a large number of samples alternatively in the absence of other modern instruments such as HPLC.

\section{Conclusions}

Diverse characteristics were observed in terms of fruit morphological traits, citrulline, and arginine levels in watermelon germplasm collections. More than $90 \%$ of the genetic resources were either redor pink-fleshed. Korean originated fruits contained intermediate levels of SSC while the USA, Russian, Tajikistan, Turkmenistan, Taiwan, and Uruguay originated fruits generally had the highest levels of soluble solids. Our results indicated that samples with high citrulline and arginine levels contained low soluble solid content, which was mainly comprised of sugar, making them less likable in terms of sweetness. Besides, red and pink colored flesh samples had less citrulline compared to yellow and orange. On the other hand, some of the primary quality traits consumers look for in a watermelon fruit include dark red flesh, high sugar content, and excellent flavor. This begs a breeding program that compromises these different quality traits with the health-beneficial compounds. In addition to the profiling of morphological characters and phytonutrients, molecular marker characterization and the identification of sources of resistance to diseases and pests are recommended for a more complete diversity analysis of watermelon genetic resources. As part of the effort in diversifying watermelon genetic resources, this study was devoted to providing baseline data on morphological quality traits and health beneficial phytonutrients of available watermelon germplasm collections in our gene bank, thereby identifying and incorporating new and quality resources into the already cultivated group.

Supplementary Materials: The following are available online at http://www.mdpi.com/2223-7747/9/9/1054/s1, Figure S1: Photos of watermelon fruit germplasm collections with wide phenotypic diversity, Table S1: Accession numbers, origin, and some selected morphological characters of the genetic resources, Figure S2: The effect of sample size (sample to solvent ratio) on instrument response of citrulline levels evaluated in two watermelon fruit samples: HPLC (a and b); CAK (c and d), Table S2: Results of the principal component analyses (for the first three $P C$ 's) of seven quantitative morphological traits for the investigated watermelon fruit samples, Table S3: Recovery test results of HPLC and Citrulline Assay Kit methods using two watermelon fruit samples, Table S4: Inter-and intra-day precision results of HPLC and Citrulline Assay kit methods using two representative watermelon fruit samples, Table S5: Results of the first three principle components of citrulline and arginine for investigated watermelon fruit samples.

Author Contributions: A.D.A., and J.-J.N. made a significant contribution to designing the experiment, analysis, drafting, and writing the manuscript. A.-J.H., J.-H.K. and M.-K.K. have made a substantial contribution to the collection and analysis of the data. O.-S.H., N.-Y.R., J.-E.L., B.-S.K., J.-H.R., H.-S.L. and J.-S.S. have participated in the conception, interpretation of data, proofreading, and revising the manuscript. J.-H.K., J.-Y.Y., and J.-J.N. recorded the phenotypic data. All authors have read and agreed to the published version of the manuscript.

Funding: This study was carried out with the support of the Research Program for Agricultural Science and Technology Development (Project No. PJ014213012019), National Institute of Agricultural Sciences, Rural Development Administration, Republic of Korea.

Conflicts of Interest: All authors have no conflict of interest to declare. The funder had no role in the design of the study, in the collection of, analysis, or interpretation of the data, in writing the manuscript, or in the decision of to publish the results.

\section{References}

1. Park, Y.H.; Cho, S.K. Watermelon production and breeding in South Korea. Isr. J. Plant Sci. 2012, 60, 415-424.

2. Wehner, T.C. Watermelon. In Vegetables I. Handbook of Plant Breeding; Prohens, J., Nuez, F., Eds.; Springer: New York, NY, USA, 2008; Volume 1, pp. 381-418.

3. Perkins-Veazie, P.; Davis, A.; Collins, J.K. Watermelon: From dessert to functional food. Isr. J. Plant Sci. 2012, 60, 37-41.

4. Liu, W.; King, S.R.; Zhao, S.; Cheng, Z.; Wan, X.; Yan, Z. Lycopene and citrulline contents in watermelon (Citrullus lanatus) fruit with different ploidy and changes during fruit development. Acta Hortic. 2010, 871, 543-550. 
5. Rimando, A.M.; Perkins-Veazie, P.M. Determination of citrulline in watermelon rind. J. Chromatogr. A 2005, 1078, 196-200. [CrossRef] [PubMed]

6. Davis, A.R.; Fish, W.W.; Levi, A.; King, S.; Wehner, T.; Perkins-veazie, P. L-Citrulline levels in watermelon cultivars from three locations. Curcubit Genet. Coop. Rep. 2010, 39, 36-39.

7. Akashi, K.; Mifune, Y.; Morita, K.; Ishitsuka, S.; Ishihara, T. Spatial accumulation pattern of citrulline and other nutrients in immature and mature watermelon fruits. J. Sci. Food Agric. 2016, 97, 479-487. [CrossRef]

8. Hartman, J.L.; Wehner, T.C.; Ma, G.; Perkins-Veazie, P. Citrulline and arginine content of taxa of Cucurbitaceae. Horticulturae 2019, 5, 22. [CrossRef]

9. Davis, A.R.; Webbber, C.L., III; Liu, W.; Perkins-veazie, P.; Levi, A.; King, S. Watermelon quality traits as affected by ploidy. HortScience 2013, 48, 1113-1118. [CrossRef]

10. Akashi, K.; Miyake, C.; Yokota, A. Citrulline, a novel compatible solute in drought-tolerant wild watermelon leaves, is an efficient hydroxyl radical scavenger. FEBS Lett. 2001, 508, 438-442. [CrossRef]

11. Fish, W.W. A reliable methodology for quantitative extraction of fruit and vegetable physiological amino acids and their subsequent analysis with commonly available HPLC systems. Food Nutr. Sci. 2012, 3, 863-871. [CrossRef]

12. Mapelli, S.; Brambilla, I.; Bertani, A. Free amino acids in walnut kernels and young seedlings. Tree Physiol. 2001, 21, 1299-1302. [CrossRef] [PubMed]

13. Curis, E.; Nicolis, I.; Moinard, C.; Osowska, S.; Zerrouk, N.; Benazeth, S.; Cynober, L. Almost all about citrulline in mammals. Amino Acids 2005, 29, 177-205. [CrossRef] [PubMed]

14. Wu, G.; Collins, J.K.; Perkins-Veazie, P.; Siddiq, M.; Dolan, K.D.; Kelly, K.A.; Heaps, C.L.; Meininger, C.J. Dietary supplementation with watermelon pomace juice enhances arginine availability and ameliorates the metabolic syndrome in zucker diabetic fatty rats. J. Nutr. 2007, 137, 2680-2685. [CrossRef]

15. Flynn, N.E.; Meininger, C.J.; Haynes, T.E.; Wu, G. The metabolic basis of arginine nutrition and pharmacotherapy. Biomed. Pharmacother. 2002, 56, 427-438. [CrossRef]

16. Young, M.; Beidler, J.; Hooshmand, S.; Figueroa, A.; Kern, M. Watermelon and L-arginine consumption improve serum lipid profile and reduce inflammation and oxidative stress by altering gene expression in rats fed an atherogenic diet. Nutr. Res. 2018, 58, 46-54.

17. Clarkson, P.; Adams, M.R.; Powe, A.J.; Donald, A.E.; McCredie, R.; Robinson, J.; McCarthy, S.N.; Keech, A.; Celermajer, D.S.; Deanfield, J.E. Oral L-arginine improves endothelium-dependent dilation in hypercholesterolemic young adults. J. Clin. Invest. 1996, 97, 1989-1994. [CrossRef]

18. Chin-Dusting, J.P.; Alexander, C.T.; Arnold, P.J.; Hodgson, W.C.; Lux, A.S.; Jennings, G.L. Effects of in vivo and in vitro L-arginine supplementation on healthy human vessels. J. Cardiovasc. Pharmacol. 1996, 28, 158-166. [CrossRef]

19. Tarazona-Diaz, M.P.; Alacid, F.; Mart, I.; Aguayo, E. Watermelon juice: Potential functional drink for sore muscle relief in athletes. J. Agric. Food Chem. 2013, 61, 7522-7528. [CrossRef]

20. Szamosi, C.; Solmaz, I.; Sari, N.; Barsony, C. Morphological characterization of Hungarian and Turkish watermelon (Citrullus lanatus (Thunb.) Matsum. et Nakai) genetic resources. Genet. Resour. Crop Evol. 2009, 56, 1091-1105. [CrossRef]

21. Solmaz, I.; Sari, N. Characterization of watermelon (Citrullus lanatus) accessions collected from Turkey for morphological traits. Genet. Resour. Crop Evol. 2009, 56, 173-188. [CrossRef]

22. Huh, Y.C.; Choi, H.S.; Solmaz, I.; Sari, N.; Kim, S. Morphological characterization of Korean and Turkish watermelon germplasm. Korean J. Agric. Sci. 2014, 41, 309-314. [CrossRef]

23. Davis, A.R.; Webber, C.L.; Fish, W.W.; Wehner, T.C.; King, S.; Perkins-veazie, P. L-Citrulline levels in watermelon cultigens tested in two environments. HortScience 2011, 46, 1572-1575. [CrossRef]

24. International Union for the Protection of New Varieties of Plants (UPOV) Watermelon, TG/142/5. Guidelines for the Conduct of Tests for Distinctness, uniformity and stabability. Available online: http://www.upov.int/ edocs/tgdocs/en/tg142.pdf (accessed on 1 April 2020).

25. Sari, N.; Solmaz, I.; Yetisir, H.; Unlu, H. Watermelon genetic resources in Turkey and their characteristics. Acta Hortic. 2007, 731, 433-438. [CrossRef]

26. Wehner, T.C.; Naegele, R.P.; Perkins-Veazie, P. Heritablity and genetic variance components associated with citrulline, arginine, and lycopene conetent in diverse watermelon cultigens. HortScience 2017, 52, 936-940. [CrossRef] 
27. Jayaprakasha, G.K.; Murthy, K.N.C.; Patil, B.S. Rapid HPLC-UV method for quantification of L-citrulline in watermelon and its potential role on smooth muscle relaxation markers. Food Chem. 2011, 127, 240-248. [CrossRef]

28. Ridwan, R.; Razak, H.R.A.; Adenan, M.I.; Saad, W.M.M. Development of isocratic RP-HPLC method for separation and quantification of L-citrulline and L-arginine in watermelons. Int. J. Anal. Chem. 2018, 2018, 4798530. [CrossRef]

29. Borges, E.M. Silica, hybrid silica, hydride silica and non-silica stationary phases for liquid chromatography. J. Chromatogr. Sci. 2015, 53, 580-597. [CrossRef]

30. Soteriou, G.A.; Siomos, A.S.; Gerasopoulos, D.; Rouphael, Y.; Georgiadou, S.; Kyriacou, M.C. Biochemical and histological contributions to textural changes in watermelon fruit modulated by grafting. Food Chem. 2017, 237, 133-140. [CrossRef]

31. Guo, S.; Zhang, J.; Sun, H.; Salse, J.; Lucas, W.J.; Zhang, H.; Zheng, Y.; Mao, L.; Ren, Y.; Wang, Z.; et al. The draft genome of watermelon (Citrullus lanatus) and resequencing of 20 diverse accessions. Nat. Genet. 2013, 45, 51-60. [CrossRef]

32. Fish, W.W. The expression of citrulline and other members of the arginine metabolic family in developing watermelon fruit. Int. J. Agric. Innov. Res. 2014, 2, 1473-2319.

33. Song, Q.; Joshi, M.; Dipiazza, J.; Joshi, V. Functional relevance of citrulline in the vegetative tissues of watermelon during abiotic stresses. Front. Plant Sci. 2020, 11, 512. [CrossRef] [PubMed]

34. Dasgan, H.Y.; Kusvuran, S.; Abak, K.; Leport, L.; Larher, F.; Bouchereau, A. The relationship between citrulline accumulation and salt tolerance during the vegetative growth of melon. Plant Soil Environ. 2009, 55, 51-57. [CrossRef]

35. Hartman, J.L.; Perkins-veazie, P.; Wehner, T.C. Citrulline and arginine are moderately heritable in two red-fleshed watermelon populations. HortScience 2019, 54, 200-205. [CrossRef]

36. Park, C.J.; Shaughnessy, M.P.; Aremenia, S.J.; Cowles, R.A. Serum citrulline levels exhibit circadian variation and fluctuations in relation to food intake in mice. Gastrocenterol. Res. 2019, 12, 88-92. [CrossRef] [PubMed]

37. Sun, J.T.; Yang, K.; Mao, J.Y.; Shen, W.F.; Lu, L.; Wu, Q.H.; Wang, Y.P.; Wu, L.P.; Zhang, R.Y. Cyanate-impaired angiogenesis: Association with poor coronary collateral growth in patients with stable angina and chronic total occlusion. J. Am. Heart Assoc. 2016, 5, 1-10. [CrossRef]

38. Muñoz-cruz, S.; Gomez-garcía, A.; Matadamas-martínez, F.; Alvarado-torres, J.A.; Meza-Cervantez, P.; Arriaga-Pizano, L.; Yepez-Mulia, L. Giardia lamblia: Identification of molecules that contribute to direct mast cell activation. Parasitol. Res. 2018, 117, 2555-2567. [CrossRef]

39. Inatomi, H.; Sasaki, T.; Suyama, Y.; Inukai, F. Meiji Daigaku, Nogakubu Kenkyu Hokoku. Bull. Chem. Soc. Jpn. 2007, 80, 2413-2417.

40. Kameya, M.; Asano, Y. Enzyme and microbial technology rapid enzymatic assays for L-citrulline and L-arginine based on the platform of pyrophosphate detection. Enzyme Microb. Technol. 2014, 57, 36-41. [CrossRef]

41. Knipp, M.; Vasak, M. A colorimetric 96-well microtiter plate assay for the determination of enzymatically formed citrulline. Anal. Biochem. 2000, 286, 257-264. [CrossRef]

42. Sugawara, K.; Yoshizawa, Y.; Tzeng, S.; Epstein, W.L.; Fukuyama, K. Colorimetric determination of citrulline residues in proteins. Anal. Biochem. 1998, 265, 92-96. [CrossRef]

(C) 2020 by the authors. Licensee MDPI, Basel, Switzerland. This article is an open access article distributed under the terms and conditions of the Creative Commons Attribution (CC BY) license (http://creativecommons.org/licenses/by/4.0/). 